\title{
La solitude et la pensée
}

\author{
France Théoret
}

The author establishes a difference between the narrator and the character of a little nine or ten-year-old girl. The context: the children she accompanies in the morning and at noon, the restrictive schedules, her work in her father's commerce... prevent her from spending any time alone. The schoolgirl discovers her internal voice while walking, alone, through the calm Chabot park. The child associates this walk with the pleasures of thinking.

La narratrice dit: Comment naît la pensée est une énigme qui se pose très tôt, avant l'adolescence?

La narratrice dit: Je n'ai pas à juger la fillette, ni sa famille, son école ou son quartier montréalais. J'affirme que la fillette est un être pensant.

Elle a neuf ou dix ans. Je l'appellerai Simone en hommage à Simone de Beauvoir. De la maison à l'école, la fillette accompagne le groupe d'enfants dont elle est l'aînée. Cette enfant parcourt les rues et traverse en diagonale le parc de Lorimier quatre fois par jour. Le trajet prend chaque fois un quart d'heure. Simone marche le matin et le midi après le repas, avec les autres enfants. Le temps presse. L'école est éloignée. La ponctualité est une vertu pour tous.

La cloche sonnera. Il faut avoir pénétré la cour avant la sonnerie.

Simone va par le chemin le plus court. Elle traverse aux mêmes intersections, choisit les trottoirs des mêmes rues. La marche compose un intervalle entre des lieux où elle n'est jamais seule. À la sortie de l'école, elle emprunte encore le plus court chemin, la diagonale du parc de Lorimier. Le sentier de terre change. Boueux sous les pluies abondantes, enneigé, glacé, composé de flaques d'eau et de neiges fondantes au printemps.

Des souliers dans des bottes de caoutchouc épais. Les pieds protégés du froid et de l'eau. Les pas cadencent la marche. Simone bouge. L'équilibriste, le souffle et la respiration. La vitesse va droit au but. Sans la course. Mais le temps presse. Elle exerce son droit à la solitude avant le travail quotidien au commerce familial. Il faut aider son père, a dit le père.

La marge est étroite. Le temps à soi n'existe pas. Apprendre à vivre ressemble à un piège. Car la crainte du faux pas érige la peur qui prend racine et grandit.

Aussi longtemps que Simone ne commet pas d'erreurs la vie va au pas. La santé est un bienfait majeur. Au milieu se tient la vertu.

Le questionnement naît au moment de la traversée du parc de Lorimier. Qu'est-ce que le bonheur, qu'est-ce que le malheur? Ce n'est pas suis-je heureuse ou suis-je malheureuse? Simone seule et solitaire, sans personne autour d'elle, 
pense. Elle perçoit qu'elle s'interroge sans intention. Ses pas avancent vers la sortie du parc. Déjà la clarté de la rue abolit sa voix intérieure.

Le lendemain, le surlendemain, les jours suivants ramènent la question. Elle éprouve une joie quand elle chemine sous les arbres à travers le parc. Cela qui s'appelle la joie importe.

La solitude, la marche, la joie sont la pensée. Simone entend sa voix qui formule une phrase: il existe un autre monde tenu caché.

La narratrice dit: Ces mots-là, je ne les ai pas oubliés. Ils ont traversé le temps, l'espace et m'ont accompagnés.

La narratrice dit: L'affiche toponymique actuelle indique le parc de Lorimier. La mémoire souscrit à un îlot rectangulaire d'arbres et de verdure qui se nommait le parc Chabot. 